\title{
Experimental Study of a Novel Direct-Expansion Variable Frequency Finned Solar/Air-Assisted Heat Pump Water Heater
}

\author{
Jing Qin, ${ }^{1}$ Jie Ji $\mathbb{D}^{1},{ }^{1}$ Wenzhu Huang, ${ }^{1}$ Hong Qin, ${ }^{2}$ Mawufemo Modjinou, ${ }^{1}$ and Guiqiang Li ${ }^{1}$ \\ ${ }^{1}$ Department of Thermal Science and Energy Engineering, University of Science and Technology of China, No. 96 Jinzhai Road, Hefei, \\ Anhui, China \\ ${ }^{2}$ Guangdong University of Technology, Guangzhou, China
}

Correspondence should be addressed to Jie Ji; jijie@ustc.edu.cn

Received 15 June 2017; Accepted 18 January 2018; Published 22 April 2018

Academic Editor: Francesco Riganti Fulginei

Copyright ( 2018 Jing Qin et al. This is an open access article distributed under the Creative Commons Attribution License, which permits unrestricted use, distribution, and reproduction in any medium, provided the original work is properly cited.

A novel direct expansion variable frequency finned solar/air-assisted heat pump water heater was fabricated and tested in the enthalpy difference lab with a solar simulator. A solar/air source evaporator-collector with an automatic lifting glass cover plate was installed on the system. The system could be operated in three modes, namely, air, solar, and dual modes. The effects of the ambient temperature, solar irradiation, compressor frequency, and operating mode on the performance of this system were studied in this paper. The experimental results show that the ambient temperature, solar irradiation, and operating mode almost have no effect on the energy consumption of the compressor. When the ambient temperature and the solar irradiation were increased, the COP was found to increase with decreasing heating time. Also, when the compressor frequency was increased, an increase in the energy consumption of the compressor and the heat gain of the evaporator were noted with a decrease in the heating time.

\section{Introduction}

Water heating consumes nearly $20 \%$ of the total energy consumption for an average family [1]. Solar energy is a clean, inexhaustible, and abundant energy resource [2]. The development of an affordable and effective clean energy technologies such as a combination of solar energy and heat pump can have huge long-term benefits, which is the concept of solar-assisted heat pump (SAHP) [3].

The concept of direct expansion solar-assisted heat pump (DX-SAHP) was first presented by Sporn and Ambrose [4]. While the "indirect-expansion SAHP" system has an intermediate heat exchanger between the solar water circuit and a water circuit, a DX-SAHP uses a two-phase solar collector to function directly as an evaporator. The evaporatorcollector configuration favourably reduces the number of components in use, which can lower the cost of the system and avoid the nighttime freeze-up problem of a traditional water collector [5].
For the SAHP system, the match between different components is critical. Liu et al. [6] found that the mass flow rate of refrigerant can match well with the thermal load of the evaporator by means of compressor frequency modulation. In this case,the compressor frequency should be adjusted according to the ambient conditions. Chaturvedi et al. [7] showed that the coefficient of performance (COP) of the system can be enhanced extensively by lowering the compressor frequency when the ambient temperatures are higher. Moreno-Rodríguez et al. [8] showed that when the condenser water flow rate is lower than $0.114 \mathrm{~kg} / \mathrm{s}$, a higher COP can be obtained by reducing the compressor frequency. However, when the water flow rate is over $0.174 \mathrm{~kg} / \mathrm{s}$, lowing the compressor frequency will drastically lead to a lower COP.

SAHP is an effective way for utilizing solar energy, but solar energy is an intermittent energy which changes greatly depending on time and weather [9]. For this reason, supplementary heat source is required to ensure the continuous and reliable operation of the SAHP. Air source heat pump 
(ASHP) can operate more reliably by absorbing heat from the ambient air [10]. However, the application of single ASHP is also dependent on the weather conditions. Especially in winter when the evaporating temperature decreases, there is a significant drop in the heating capacity and energy efficiency of the system [11] in good shape. Since SAHP and ASHP have their respective advantages and disadvantages, many researchers combined SAHP and ASHP to improve the reliability of the system. The current dual source heat pump system is made up of different heat exchangers to utilize different heat sources, which would involve more complicated equipment and cause higher cost and other related issues [12-14]. A dual source evaporator-collector, which is made up of finned copper tubes with selective absorption coating is fabricated in this study to improve the performance of the dual source heat pump system. The dual source evaporatorcollector configuration could effectively reduce the number of components in use and absorb more heat from solar and air than flat plate evaporator through the fins.

Glazed and unglazed flat plate solar collectors are two major collector types mostly used in SAHP systems [15]. When the temperature of the collector system is higher than the ambient temperature, the use of glazed solar collector will reduce heat loss [16], while, when the temperature of the collector is lower than the ambient temperature, the use of unglazed solar collector produces high heat efficiency [17]. Therefore, an automatic lifting glass cover plate, which could automatically cover and uncover the evaporator-collector, is expected to enhance the performance of SAHP system.

Therefore, there are three approaches to enhance the performance of a solar-assisted heat pump water heater (SAHPWH) system: (1) variable frequency compressor; (2) a dual source evaporator-collector made up of finned copper tubes with selective absorption coating; and (3) an automatic lifting glass cover plate. However, there is no system in published experimental studies that applied all three components above to improve the performance of SAHPWH system. In this paper, a novel DX-SAHPWH system that applied all three components above was fabricated and tested experimentally.

Most studies of SAHP were implemented in outdoor environment where constant solar radiation and ambient temperature are hard to maintain [18]. In this study, the experiment was carried out under constant and controlled solar irradiation and ambient temperature in the enthalpy difference lab with a solar simulator to produce better results.

In this paper, a novel DX-SAHPWH system was experimentally investigated and tested in the enthalpy difference lab with a solar simulator. The effects of the ambient temperature, solar irradiation, compressor frequency, and the operating modes on the performance of this system were studied.

\section{System Description and Test Apparatus}

2.1. System Description. Figure 1 shows the schematic diagram of the DX-SAHPWH system. This system mainly consists of a solar/air source horizontal finned evaporator-collector, a R410a hermetic rotary DC inverter compressor, a plate-type heat exchanger condenser, a $150 \mathrm{~L}$ pressure bearing structure water-storage tank, and an electronic expansion valve.
In this system, the refrigerant absorbs energy from the air and solar; and gets vaporized in the evaporator-collector. Then, it is compressed in the compressor and becomes superheated vapor of high temperature and pressure. The vapor enters the condenser and gets condensed into liquid. The heat rejected in this procedure is absorbed by water-storage tank. Therefore, the water is heated. After this, the refrigerant passes through the electronic expansion valve where it expands irreversibly and adiabatically. Finally, the refrigerant flows back to the evaporator-collector and gets vaporized again, the cycle to continues.

As shown in Figure 2, the evaporator-collector is made up of finned copper tubes with selective absorption coating to increase the area for absorbing solar and air energy, its main parameters are shown in Table 1. A fan is also installed at the back of the evaporator-collector. Besides, an automatic lifting glass cover plate, which can be used to cover and uncover the evaporator-collector automatically, was fabricated on the top of the evaporator-collector, as shown in Figure 3.

Based on the operating conditions of the glass cover plate and fan, this system could be operated in three modes, namely, air, solar, and dual modes, although the system could absorb energy from both air and solar in three working modes, as shown in Table 2.

2.2. Test Apparatus. To study the performance of the DXSAHPWH system, the system has been tested in the enthalpy difference lab with a solar simulator. The enthalpy difference lab can maintain constant ambient temperature and humidity by operating the air handling units (AHU), as shown in Figure 4. The AHU consists of coolers, heaters, humidifier, and fan, which offer cooling capacity, heating capacity, controllable humidity, and air cycle in the lab, respectively. The solar simulator was then configured in the lab to simulate solar irradiation on the surface of the evaporatorcollector. As the spectrum distribution satisfies the national class B level standard, and the heterogeneity and instability of the solar simulator are under 5\%, the solar simulator effectively simulated the solar irradiation for the study. Its luminous area is $2 \times 2 \mathrm{~m}^{2}$, and the adjustable range of the irradiance is from 0 to $1200 \mathrm{~W} / \mathrm{m}^{2}$. The solar simulator was set parallel to the collectors. Hence, the influence of solar irradiation on this system can be studied.

Ambient dry bulb and wet bulb temperature of the enthalpy difference lab was measured using platinum resistance thermometer (with grade A accuracy). The temperatures of water in the storage tank, at the inlet and outlet of the evaporator-collector, the compressor, the condenser, and the electronic expansion valve were measured using $\mathrm{T}$ type copper-constantan thermocouples. Also, the refrigerant pressure in evaporator-collector and condenser was measured using Huba pressure sensor. The solar irradiance and the energy consumption of the system were also measured and recorded during the experiments. A digital power meter (YOKOGAWA WT230) was used to measure the energy consumption of the system. The experimental data was recorded automatically for every 6 seconds by a data logger (Agilent 34970A). The details of the sensors and measurement instruments are shown in Table 3. 


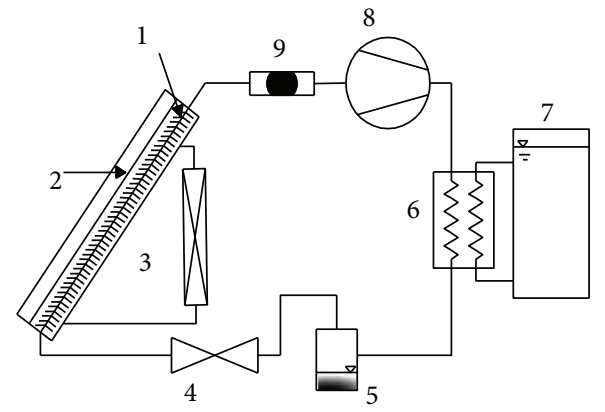

(a)
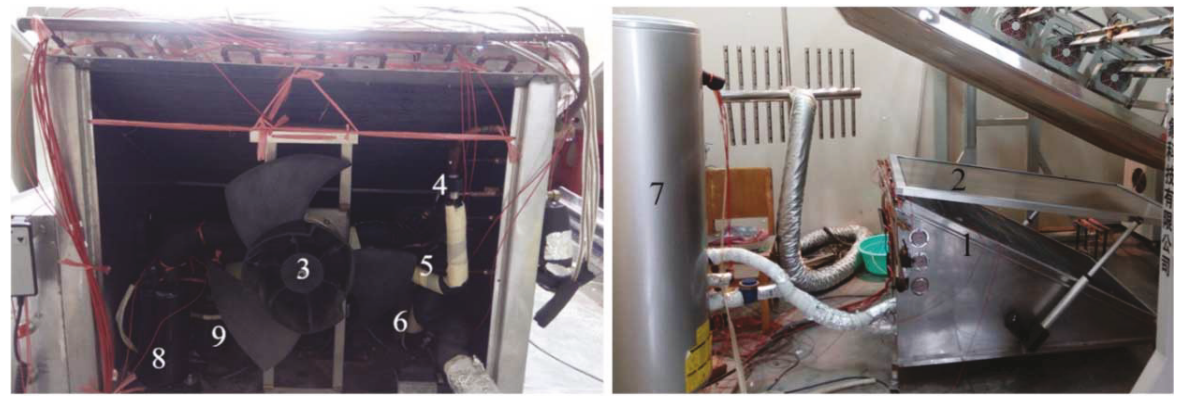

(b)

FIGURE 1: Configuration diagram of the DX-SAHPWH system. (a) Schematic. (b) Photo. 1: solar/air source horizontal finned evaporatorcollector; 2: automatic lifting glass cover plate; 3: fan; 4: electronic expansion valve; 5: accumulator; 6: condenser; 7: water tank; 8: variable frequency compressor; 9: strainer.

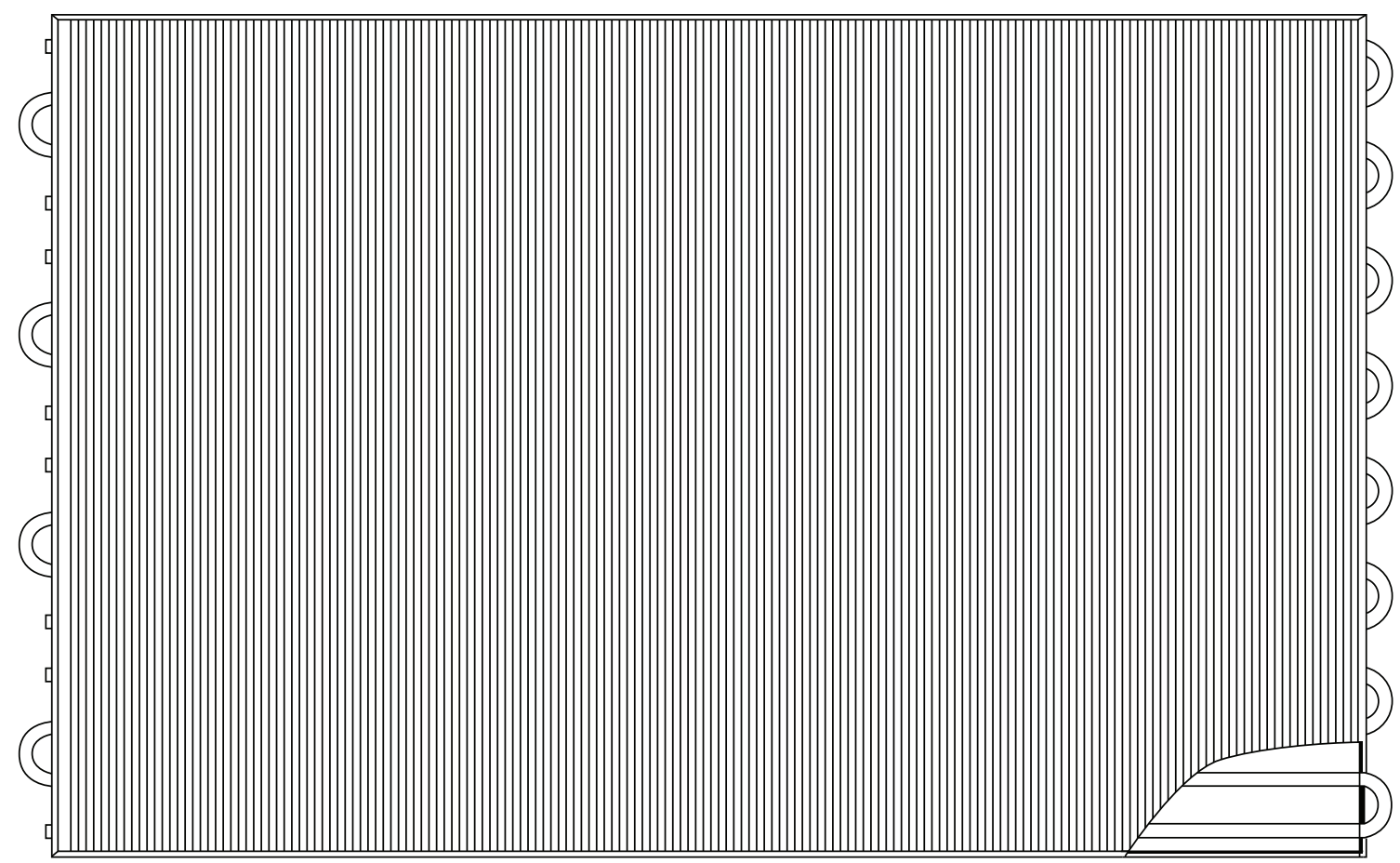

(a)

FIgURE 2: Diagram of the evaporator-collector. (a) Front view. (b) Lateral view. 
TABLE 1: Parameters of evaporator-collector.

\begin{tabular}{lc}
\hline Length & $1475 \mathrm{~mm}$ \\
Width & $800 \mathrm{~mm}$ \\
Solar absorptivity of selective absorption coating & 0.95 \\
Transmittance of glass plate & 0.85 \\
External diameter of copper tube & $9.52 \mathrm{~mm}$ \\
Thickness of copper tube & $0.35 \mathrm{~mm}$ \\
Number of tube rows & 16 \\
Thickness of fin & $0.35 \mathrm{~mm}$ \\
Punching diameter of fin & $10 \mathrm{~mm}$ \\
Height of fin & $15 \mathrm{~mm}$ \\
Vertical pitch of fin & $3 \mathrm{~mm}$ \\
Number of fins & 208 \\
Angle of fin and copper tube & $28^{\circ}$ \\
\hline
\end{tabular}

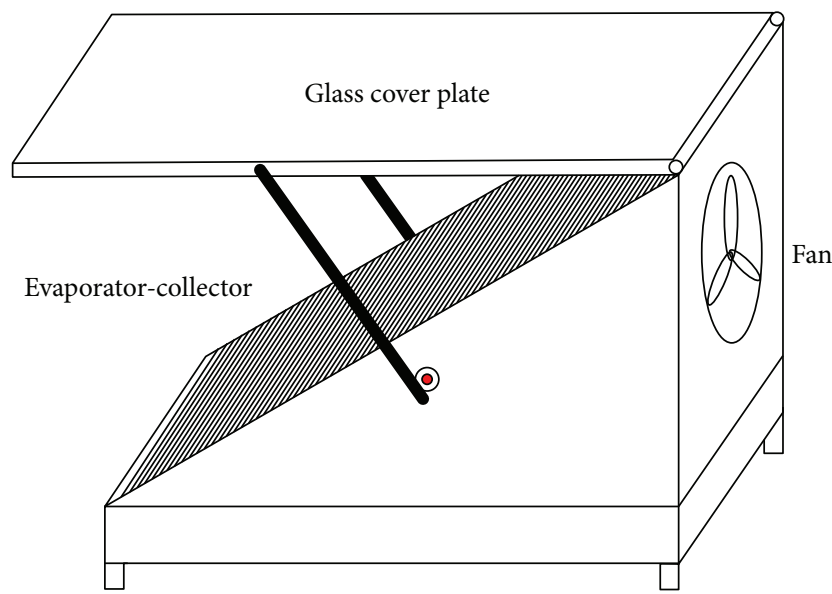

FIGURE 3: Automatic lifting glass cover plate.

TABLE 2: Three operating modes of the DX-SAHPWH system.

\begin{tabular}{lccc}
\hline Component & Air mode & Solar mode & Dual mode \\
\hline Glass cover plate & Uncover & Cover & Uncover \\
Fan & Fast & Off & Slow \\
\hline
\end{tabular}

\section{Thermodynamic Analysis Methods}

For this system, the total energy consumption $W_{\text {sys }}$ is the sum of the energy consumption of the compressor, water pump, fan, and electric controller.

$$
W_{\text {sys }}=W_{\text {com }}+W_{\text {pump }}+W_{\text {fan }}+W_{\text {ele }} \text {, }
$$

where $W_{\text {com }}, W_{\text {pump }}, W_{\text {fan }}$, and $W_{\text {ele }}$ represent the energy consumption of the compressor, water pump, fan, and electric controller, respectively. In this system, $W_{\text {pump }}$ is $60 \mathrm{~W}$ and $W_{\text {ele }}$ is $10 \mathrm{~W} . W_{\text {fan }}$ is $0 \mathrm{~W}$ in solar mode and $100 \mathrm{~W}$ in dual and air modes.

For the compressor, the refrigerant gas temperatures $\left(T_{\mathrm{d}}, T_{\mathrm{s}}\right)$ and pressures $\left(P_{\mathrm{d}}, P_{\mathrm{s}}\right)$ at the discharge and suction ends of the compressor, respectively, are related by the compression index $\gamma$ as follows:

$$
\frac{T_{\mathrm{d}}}{T_{\mathrm{s}}}=\left(\frac{P_{\mathrm{d}}}{P_{\mathrm{s}}}\right)^{\gamma-1 / \gamma} .
$$

The rotating speed $n$ of the compressor is influenced by the inverter frequency.

$$
n=\frac{120 \times f \times(1-s)}{p},
$$

where $p$ is motor magnetic series and $s$ is motor transfer ratio.

The mass flow rate $m_{\mathrm{r}}$ of the refrigerant is given by

$$
m_{\mathrm{r}}=\frac{\eta_{\mathrm{v}} n V_{\mathrm{d}}}{60 v_{\mathrm{s}}}
$$

where $\eta_{\mathrm{v}}$ is the volumetric efficiency, $V_{\mathrm{d}}$ is the displacement volume, and $v_{\mathrm{s}}$ is the specific volume of refrigerant gas at compressor suction.

According to the first law of thermodynamics, the heat absorbed by the evaporator-collector $Q_{e}$ should be equal to heat gain of the refrigerant.

$$
Q_{\mathrm{e}}=m_{\mathrm{r}}\left(h_{\mathrm{r}, \text { out }}-h_{\mathrm{r}, \text { in }}\right),
$$

where $h_{\mathrm{r} \text {,out }}$ is refrigerant enthalpy leaving the evaporatorcollector and $h_{\mathrm{r} \text {,in }}$ is refrigerant enthalpy entering the evaporator-collector.

The theoretical power consumption $W_{\text {th }}$ is given by

$$
W_{\text {th }}=\eta_{\mathrm{v}} V_{\mathrm{d}} P_{\mathrm{s}} \frac{n}{60} \frac{\gamma}{\gamma-1}\left[\left(\frac{P_{\mathrm{d}}}{P_{\mathrm{s}}}\right)^{\gamma-1 / \gamma}-1\right] \text {. }
$$

In combination with the above two formulas, $W_{\text {th }}$ could also be

$$
W_{\text {th }}=\eta_{\mathrm{v}} V_{\mathrm{d}} P_{\mathrm{s}} \frac{n}{60} \frac{\gamma}{\gamma-1}\left[\left(\frac{T_{\mathrm{d}}}{T_{\mathrm{s}}}\right)-1\right] .
$$

The input power consumption $W_{\text {com }}$ of the compressor is given by

$$
W_{\text {com }}=\frac{W_{\text {th }}}{\eta_{\mathrm{i}} \eta_{\mathrm{m}} \eta_{\mathrm{mo}}},
$$

where $\eta_{\mathrm{i}}, \eta_{\mathrm{m}}$, and $\eta_{\mathrm{mo}}$ are the indicated efficiency, mechanical efficiency, and motor efficiency, respectively.

The instantaneous heat exchange rate of this system is calculated by

$$
Q_{\mathrm{sys}}=c_{\mathrm{w}} m_{\mathrm{w}} \frac{d T_{\mathrm{w}}}{d t}
$$

where $c_{\mathrm{w}}$ represents the specific heat capacity of water, $m_{\mathrm{w}}$ is the gross mass of water in the tank, and $T_{\mathrm{w}}$ stands for the water temperature.

The fundamental and predominant performance evaluation approach for the DX-SAHPWH system is coefficient of the performance (COP). It is defined as the ratio of heat exchange rate of the system $Q_{\text {sys }}$ to the energy consumption 


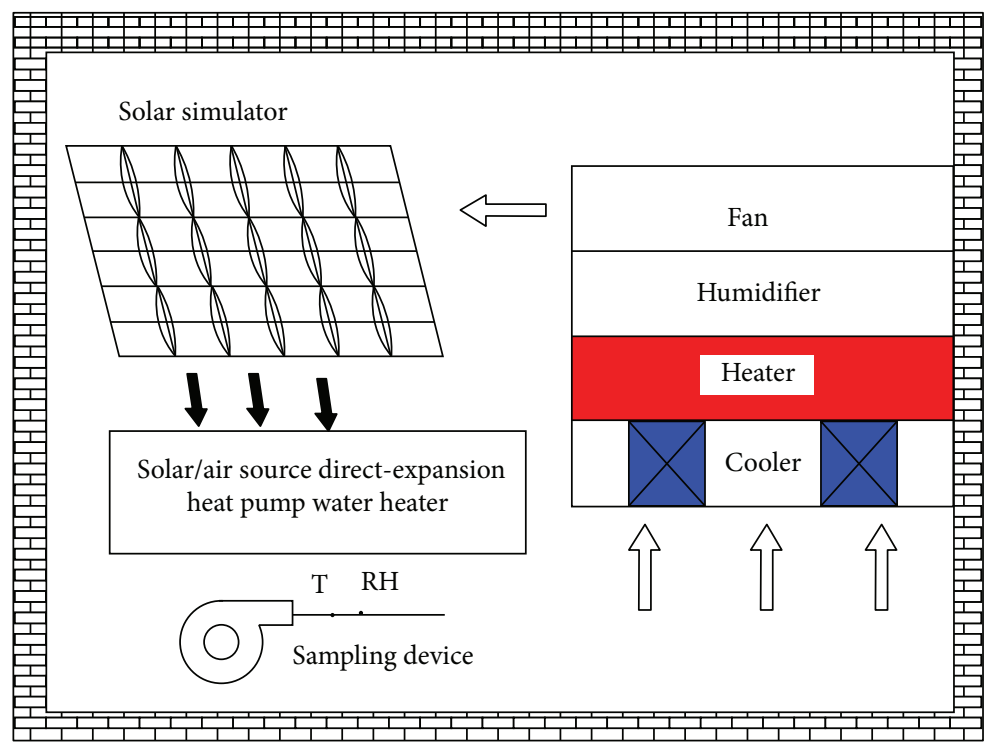

(a)

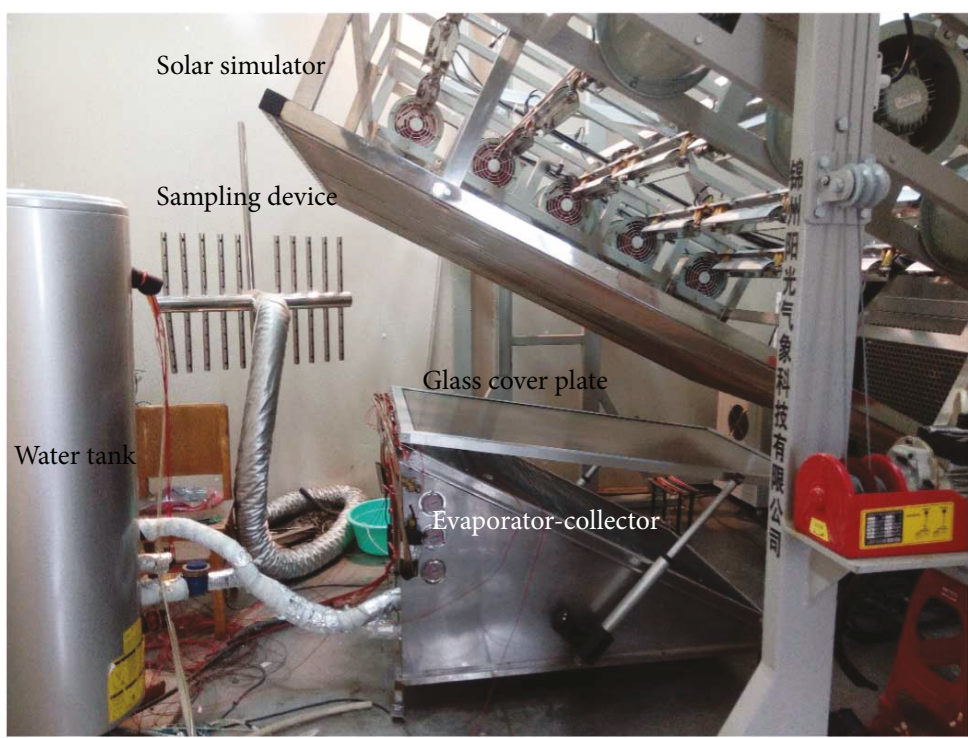

(b)

FIgure 4: Configuration diagram of the enthalpy difference lab. (a) Schematic. (b) Photo.

TABLE 3: Characteristics of sensors and measurement instruments.

\begin{tabular}{lccc}
\hline Parameter & Range & Accuracy & Measuring apparatus \\
\hline Temperature $\left({ }^{\circ} \mathrm{C}\right)$ & -100 to 100 & \pm 0.2 & T-type thermocouple \\
Pressure $(\mathrm{MPa})$ & $0-3.04$ & $0.3 \%$ & Huba pressure sensor \\
Irradiance $\left(\mathrm{W} / \mathrm{m}^{2}\right)$ & $0-2000$ & $2 \%$ & Pyranometer \\
Power $(\mathrm{kW})$ & $0-12$ & $1.2 \%$ & YOKOGAWA power sensor WT230 \\
\hline
\end{tabular}

of the system $W_{\text {sys }}$. This description is mathematically stated as
Based on (1), (9), and (10), instantaneous COP can be expressed by

$$
\mathrm{COP}=\frac{Q_{\text {sys }}}{W_{\text {sys }}}
$$

$$
\mathrm{COP}_{\mathrm{i}}=\frac{c_{\mathrm{w}} m_{\mathrm{w}}\left(d T_{\mathrm{w}} / d t\right)}{W_{\text {com }}+W_{\text {pump }}+W_{\text {fan }}+W_{\text {ele }}} .
$$


The average COP with the water temperature rising from the initial value $T_{\text {ini }}$ to the final value $T_{\text {fin }}$ is

$$
\mathrm{COP}_{\mathrm{m}}=\frac{\int Q_{\text {sys }}}{\int W_{\text {sys }}}=\frac{c_{\mathrm{w}} m_{\mathrm{w}}\left(T_{\mathrm{fin}}-T_{\mathrm{ini}}\right)}{\int\left(W_{\text {com }}+W_{\text {pump }}+W_{\text {fan }}+W_{\text {ele }}\right)} .
$$

Since the heat absorbed by the evaporator-collector includes convectional and radiant heat exchanging, $Q_{e}$ can also be expressed by

$$
Q_{\mathrm{e}}=A\left(K_{\mathrm{e} i} \Delta T_{\mathrm{m}}+\alpha_{\mathrm{e}} R\right),
$$

where $A$ is the heat exchanging area of the evaporatorcollector. $i=1,2,3$, and $K_{\mathrm{e} 1}, K_{\mathrm{e} 2}, K_{\mathrm{e} 3}$ stands for convectional heat exchanging coefficient of the evaporator-collector in solar, dual, and air mode, respectively. According to the difference of wind speed in each mode, $K_{\mathrm{e} 1}, K_{\mathrm{e} 2}, K_{\mathrm{e} 3}$ is different, and $K_{\mathrm{e} 1} \leq K_{\mathrm{e} 2}<K_{\mathrm{e} 3} \cdot \Delta T_{\mathrm{m}}$ is the mean temperature difference of convectional heat exchanging; $\alpha_{\mathrm{e}}$ is the absorptivity of the evaporator-collector; $R$ is the intensity of solar irradiation.

\section{Experiment Results and Discussion}

4.1. Effect of the Solar Irradiation on Heat Performance of the System. According to GB/T 23137-2008, the nominal working conditions of heat pump water heater were chosen as the test conditions, which was set to an ambient temperature of $20^{\circ} \mathrm{C}$, an ambient relative humidity of $59 \%$, and the water temperature rising from $15^{\circ} \mathrm{C}$ to $55^{\circ} \mathrm{C}$. To investigate the effect of the solar irradiation on heat performance of this system, the experiments were taken under above conditions and the solar irradiation set at $500 \mathrm{~W} / \mathrm{m}^{2}$ and $900 \mathrm{~W} / \mathrm{m}^{2}$. The results are shown in Figures 5-9.

As illustrated in Figure 5, $W_{\text {com }}$ increases significantly with the rising water temperature. The reason is that when $T_{\mathrm{w}}$ increases, $T_{\mathrm{d}}, T_{\mathrm{s}}, P_{\mathrm{d}}$, and $P_{\mathrm{s}}$ increase as well with a decrease in $\eta_{\mathrm{m}}$ and the increment of $T_{\mathrm{d}}$ is significantly larger than the increment of $T_{s}$, so when $P_{s}$ and $T_{\mathrm{d}} / T_{\mathrm{s}}$ both is increased, according to (7) and (8), $W_{\text {com }}$ will increase significantly. Besides when the solar irradiation increases from $500 \mathrm{~W} / \mathrm{m}^{2}$ to $900 \mathrm{~W} / \mathrm{m}^{2}, P_{\mathrm{s}}$ is found to be almost the same, so was $W_{\text {com }}$. And when the operating mode is set different, $P_{\mathrm{s}}$ shows no significant difference, so $W_{\text {com }}$ is almost the same.

As shown in Figure 6, when solar irradiation increases from $500 \mathrm{~W} / \mathrm{m}^{2}$ to $900 \mathrm{~W} / \mathrm{m}^{2}$, the heat absorbed from solar irradiation by the evaporator-collector increases, so $Q_{\mathrm{e}}$ increases. $Q_{\mathrm{e}}$ decreases with the rising of the water temperature. The reason is that with the rising of the water temperature, the evaporator temperature increases, which means the mean temperature difference of convectional heat exchanging $\Delta T_{\mathrm{m}}$ decreases, thus the heat absorbed from air by the evaporator decreases.

As shown in Figure 7, when the solar irradiation is increased from $500 \mathrm{~W} / \mathrm{m}^{2}$ to $900 \mathrm{~W} / \mathrm{m}^{2}, W_{\text {com }}$ is almost the same and $Q_{e}$ is higher, so $\mathrm{COP}_{\mathrm{i}}$ is higher. And with the rising of the water temperature, $Q_{\mathrm{e}}$ decreases and $W_{\text {com }}$ increased, so $\mathrm{COP}_{\mathrm{i}}$ decrease. And there are three reasons for high $\mathrm{COP}_{\mathrm{i}}$ when $T_{\mathrm{w}}$ is low. First, when $T_{\mathrm{w}}$ is low, $P_{\mathrm{s}}$ and $T_{\mathrm{d}} / T_{\mathrm{s}}$ are small, according to (7) and (8), $W_{\text {com }}$ is small. Second, the refrigerant temperature in the evaporator is very low when

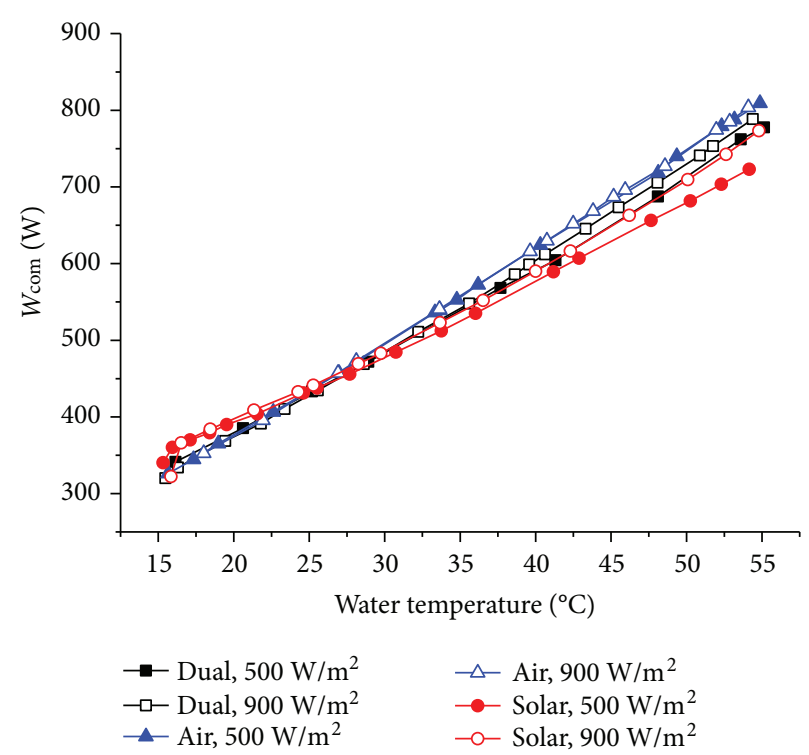

FIgURE 5: Effect of the solar irradiation on $W_{\text {com }}$.

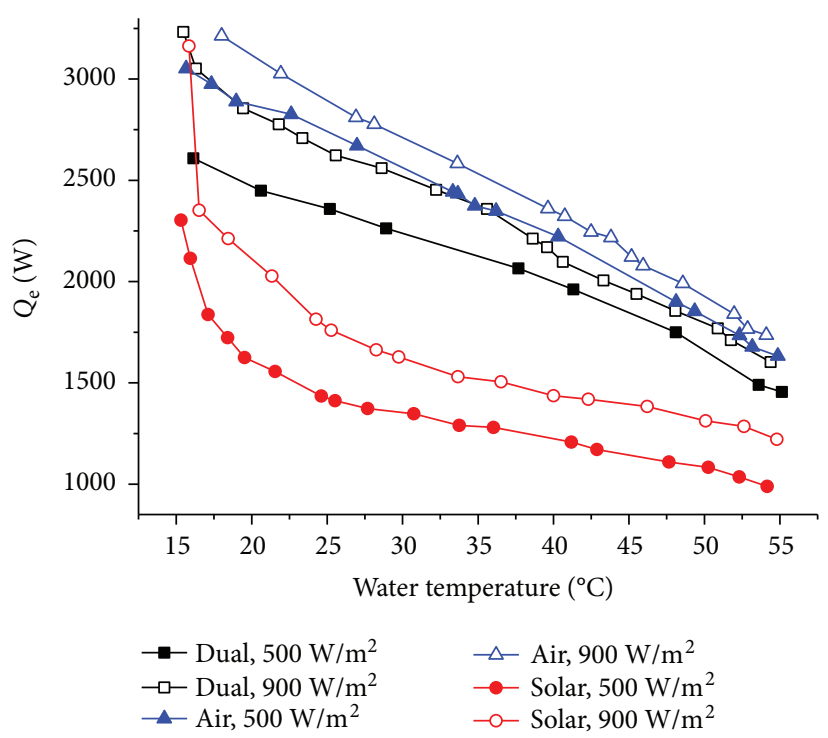

FIgURE 6: Effect of the solar irradiation on $Q_{\mathrm{e}}$.

$T_{\mathrm{w}}$ is low, so the refrigerant could absorb more energy from air. Finally, before the system is turned on, the solar simulator needs to be adjusted for $50 \mathrm{~min}$ or so, and the evaporatorcollector could absorb a lot of energy from the solar simulator during this period. After the system is turned on, the energy absorbed by the evaporator-collector will be transfered to the water. Therefore, when $T_{\mathrm{w}}$ are low, $W_{\text {com }}$ is low and $Q_{\mathrm{e}}$ is very high, and so $\mathrm{COP}_{\mathrm{i}}$ is found to be very high.

As described in Figures 8 and $9, \mathrm{COP}_{\mathrm{m}}$ is higher and heating time for the water temperature rising from $15^{\circ} \mathrm{C}$ to $55^{\circ} \mathrm{C}$ is less when the solar irradiation is higher, because the evaporator-collector can absorb more heat from solar irradiation under higher solar irradiation, which will speed up the heating process and increases the average COP. 


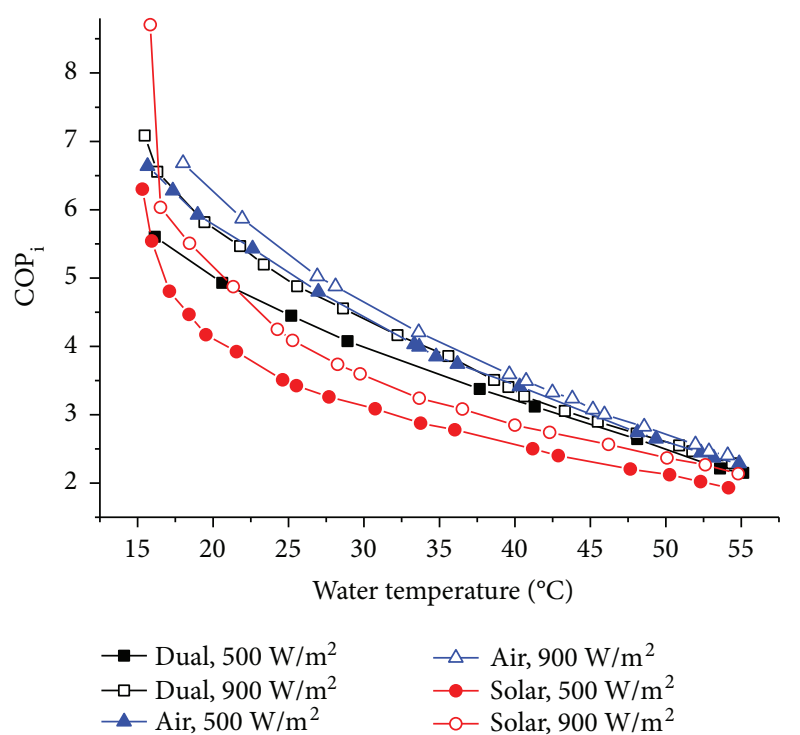

FIGURE 7: Effect of the solar irradiation on $\mathrm{COP}_{\mathrm{i}}$.

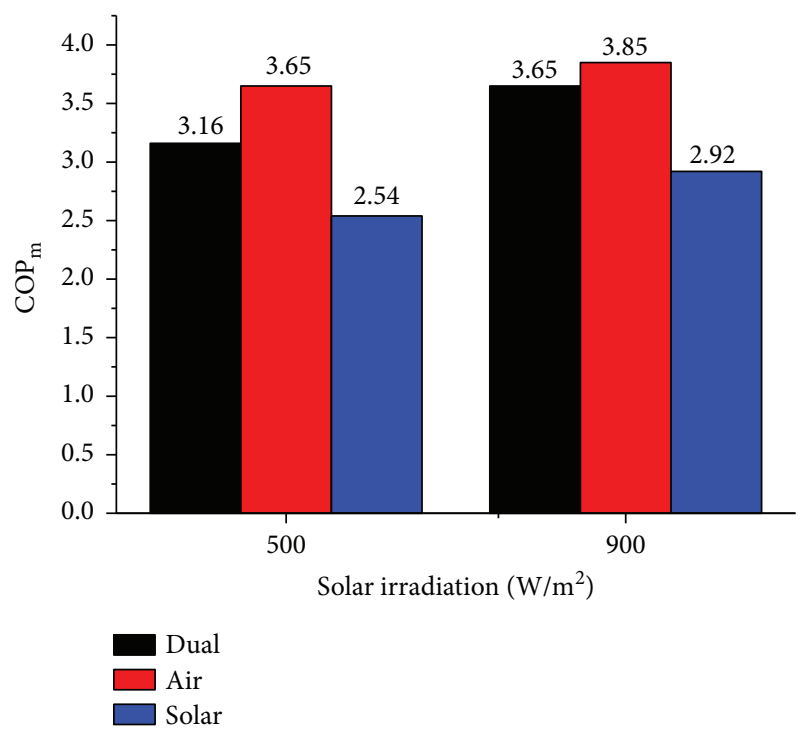

Figure 8: Effect of the solar irradiation on $\mathrm{COP}_{\mathrm{m}}$.

When the solar irradiation increases from $500 \mathrm{~W} / \mathrm{m}^{2}$ to $900 \mathrm{~W} / \mathrm{m}^{2}, \mathrm{COP}_{\mathrm{m}}$ increases by $0.20,0.49$, and 0.38 in air, dual, and solar modes, respectively. And the heating time decreases by $7.5 \mathrm{~min}, 23.5 \mathrm{~min}$, and $39.5 \mathrm{~min}$ in air, dual, and solar modes, respectively.

4.2. Effect of the Ambient Temperature on Heat Performance of the System. To investigate the effect of the ambient temperature on heat performance of the system, experiments were done under the following conditions of water temperature rising from $15^{\circ} \mathrm{C}$ to $55^{\circ} \mathrm{C}$, ambient relative humidity of $59 \%$, the solar irradiation of $900 \mathrm{~W} / \mathrm{m}^{2}$, the compressor frequency of $30 \mathrm{~Hz}$, and the ambient temperature of $20^{\circ} \mathrm{C}$ and $30^{\circ} \mathrm{C}$. Results are shown in Figures 10-12 and Table 4.

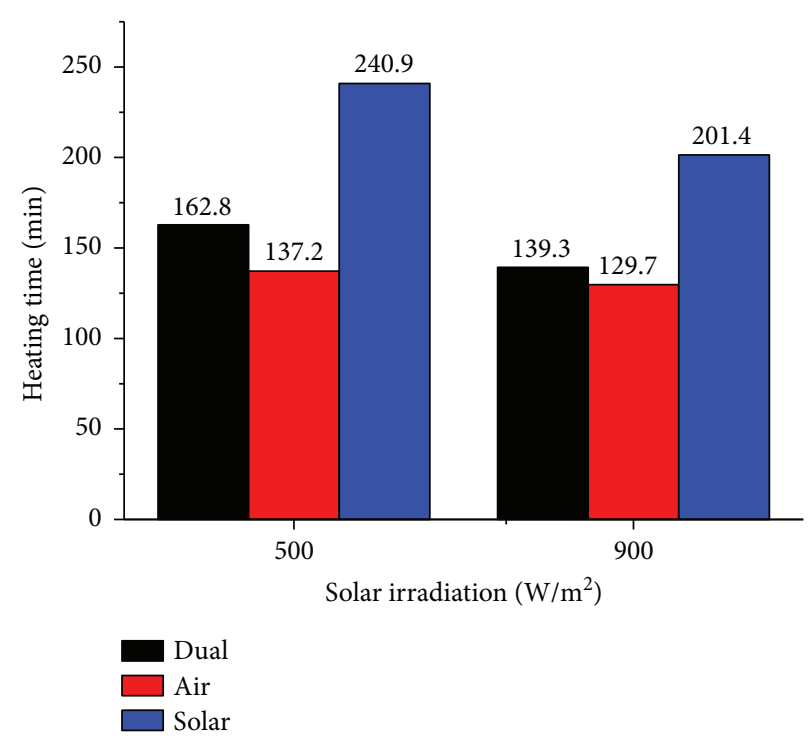

FIGURE 9: Effect of the solar irradiation on heating time.

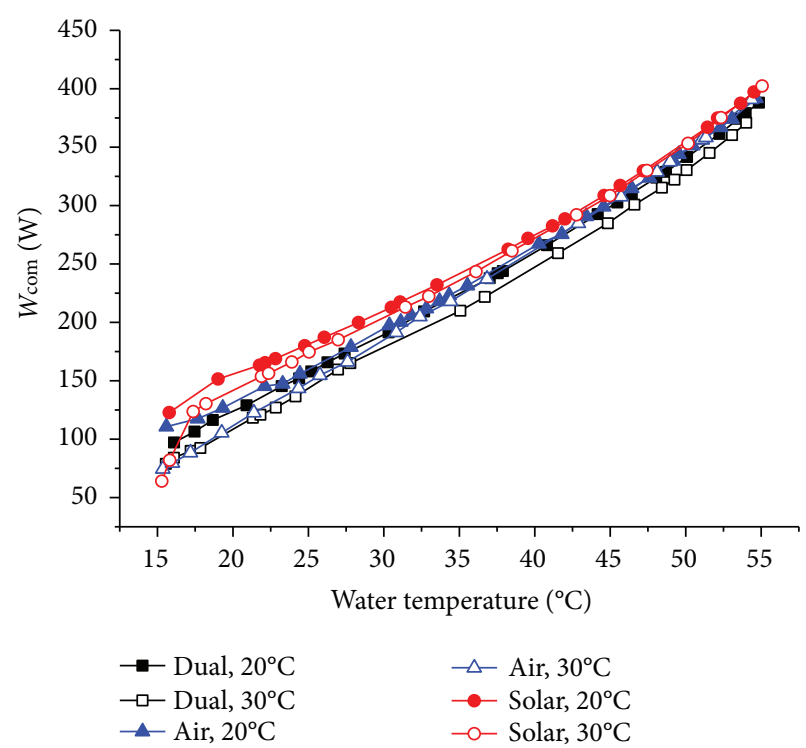

FIgURE 10: Effect of the ambient temperature on $W_{\text {com }}$.

As described in Figure 10, when the ambient temperature rises from $20^{\circ} \mathrm{C}$ to $30^{\circ} \mathrm{C}$, the increment of $P_{s}$ can be neglected, so $W_{\text {com }}$ is almost the same.

As presented in Figure 11, when the ambient temperature is higher, the mean temperature difference of convectional heat exchanging $\Delta T_{\mathrm{m}}$ increases, so the energy absorbed from air by the evaporator-collector increases, which leads to a higher $Q_{\mathrm{e}}$.

As shown in Figure 12, when the ambient temperature rises from $20^{\circ} \mathrm{C}$ to $30^{\circ} \mathrm{C}, W_{\text {com }}$ is almost the same, $Q_{e}$ is higher, so $\mathrm{COP}_{\mathrm{i}}$ is higher. It is noteworthy that after the water temperature rises to $52^{\circ} \mathrm{C}, \mathrm{COP}_{\mathrm{i}}$ decreases below 1.00 in air mode, which means that the performance of this system is not better than electric water heater. The reason is that the heat exchange rate of the evaporator-collector is extremely 


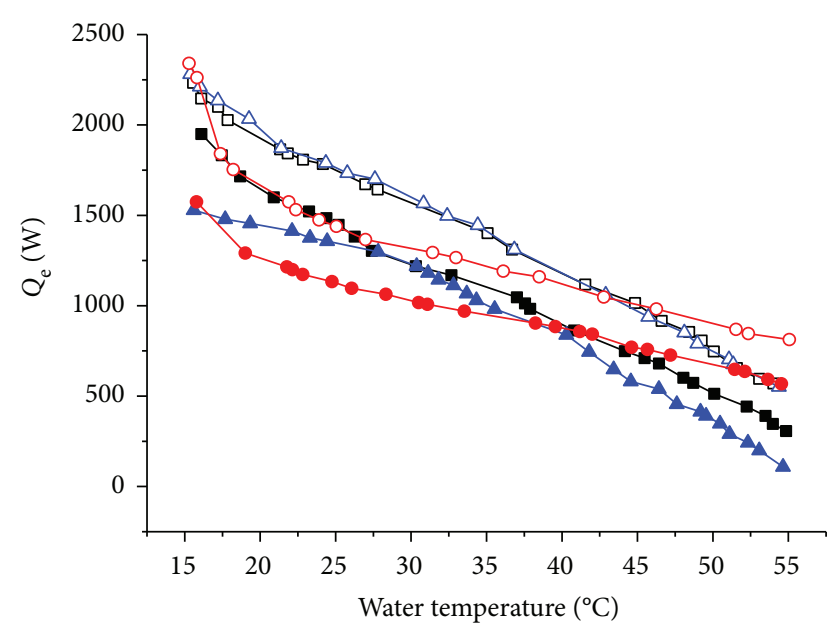

$\begin{array}{ll}\rightarrow-\text { Dual, } 20^{\circ} \mathrm{C} & - \text { Air, } 30^{\circ} \mathrm{C} \\ \longrightarrow-\text { Dual, } 30^{\circ} \mathrm{C} & - \text { Solar, } 20^{\circ} \mathrm{C} \\ - \text { Air, } 20^{\circ} \mathrm{C} & - \text { Solar, } 30^{\circ} \mathrm{C}\end{array}$

FIgURE 11: Effect of the ambient temperature on $Q_{\mathrm{e}}$.

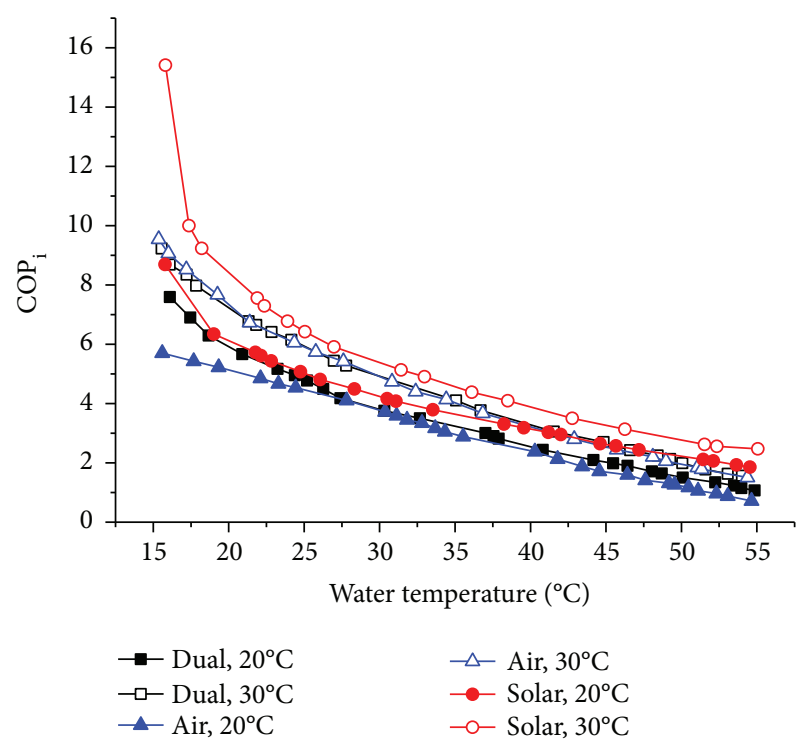

FIGURE 12: Effect of the ambient temperature on $\mathrm{COP}_{\mathrm{i}}$.

TABLE 4: Effect of the ambient temperature on average COP and heating time.

\begin{tabular}{lcccccc}
\hline Ambient temperature & \multicolumn{4}{c}{ Average COP } & \multicolumn{3}{c}{ Heating time (min) } \\
$\left({ }^{\circ} \mathrm{C}\right)$ & Air & Solar & Dual & Air & Solar & Dual \\
\hline 20 & 2.23 & 3.35 & 2.65 & 382.2 & 336.6 & 328.8 \\
30 & 3.40 & 4.15 & 3.48 & 260 & 276.3 & 262.2 \\
\hline
\end{tabular}

low and the energy consumption of the compressor is too high after the water temperature rises to $52^{\circ} \mathrm{C}$.

As shown in Table 4, when the ambient temperature is higher, $\mathrm{COP}_{\mathrm{m}}$ is higher and heating time is less. Because when the ambient temperature is higher, the mean temperature difference of convectional heat exchanging $\Delta T_{\mathrm{m}}$

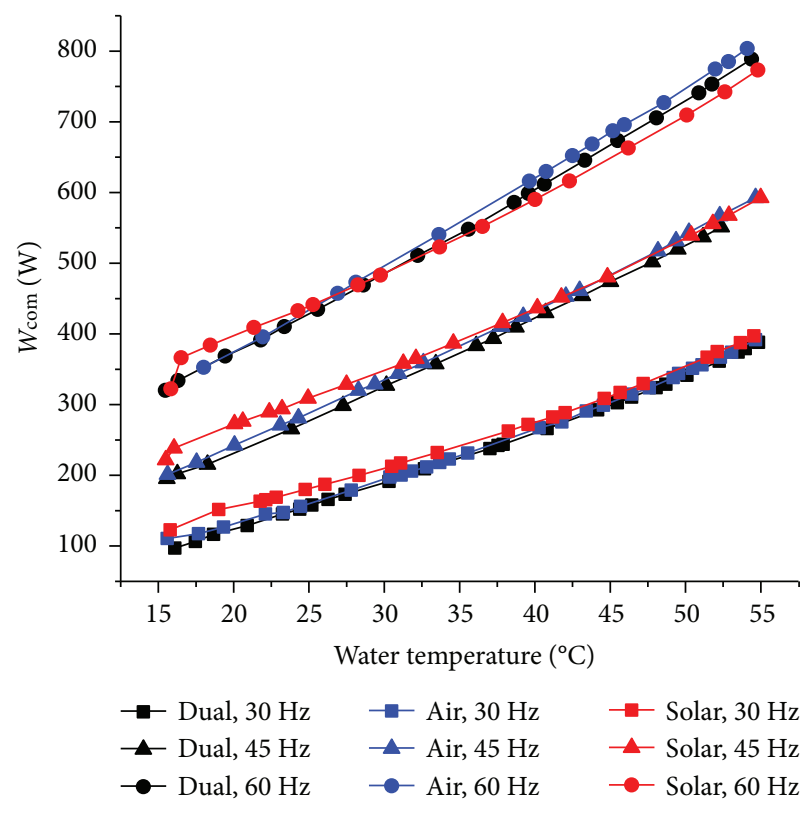

FIGURE 13: Effect of the compressor frequency on $W_{\text {com }}$.

increases; therefore, the evaporator-collector could absorb more energy from air, which will accelerate the heating process and raise average COP.

4.3. Effect of the Compressor Frequency on Heat Performance of the System. To investigate the effect of the compressor frequency on heat performance of the system, experiments were done under the following conditions of an ambient temperature of $20^{\circ} \mathrm{C}$, the ambient relative humidity of $59 \%$, the solar irradiation of $900 \mathrm{~W} / \mathrm{m}^{2}$, and the compressor frequency of $30 \mathrm{~Hz}, 45 \mathrm{~Hz}$, and $60 \mathrm{~Hz}$. The results are shown in Figures 13-17.

As illustrated in Figure 13, according to (3) and (7), when the compressor frequency increases, the rotating speed of compressor $n$ increases, so $W_{\text {com }}$ increases. For the system working in different operating modes, $P_{\mathrm{s}}$ is almost the same, so $W_{\text {com }}$ is almost same.

As presented in Figure 14, $Q_{\mathrm{e}}$ decreases with the increment of $T_{\mathrm{w}}$ and increases with the rising of the compressor frequency. According to (3), (4), and (5), when the compressor frequency $f$ increases, the rotating speed $n$ of the compressor increases, then the mass flow rate of the refrigerant $m_{\mathrm{r}}$ increases, so $Q_{\mathrm{e}}$ increases.

As shown in Figure 15, since the compressor frequency could both affect $W_{\text {com }}$ and $Q_{e}$, the changing of $\mathrm{COP}_{\mathrm{i}}$ is more complicated under different compressor frequencies. In air mode, $\mathrm{COP}_{i}$ is higher when the compressor frequency is higher. In solar mode, $\mathrm{COP}_{\mathrm{i}}$ is higher when the compressor frequency is lower. And the difference of $\mathrm{COP}_{i}$ gradually decreased to 0 after the water temperature increases to $45^{\circ} \mathrm{C}$. In dual mode, before the water temperature rises to $23^{\circ} \mathrm{C}, \mathrm{COP}_{\mathrm{i}}$ is higher when the compressor frequency is lower and, afterwards, $\mathrm{COP}_{\mathrm{i}}$ is higher when the compressor frequency is higher.

As shown in Figures 16 and 17, heating time for the water temperature rising from $15^{\circ} \mathrm{C}$ to $55^{\circ} \mathrm{C}$ is less when the 


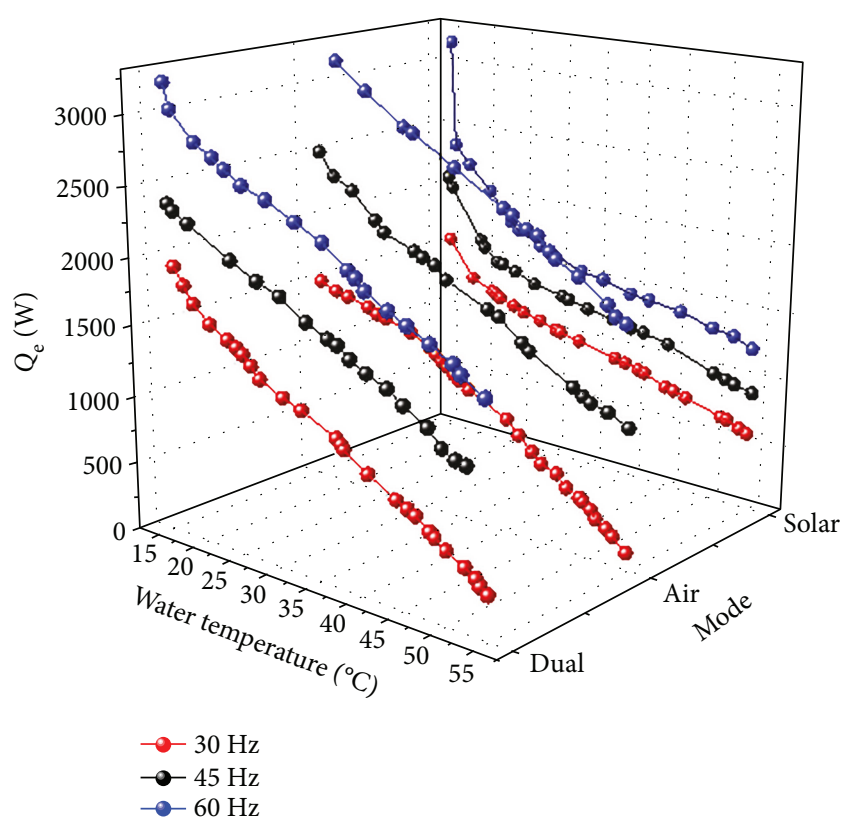

Figure 14: Effect of the compressor frequency on $Q_{\mathrm{e}}$.

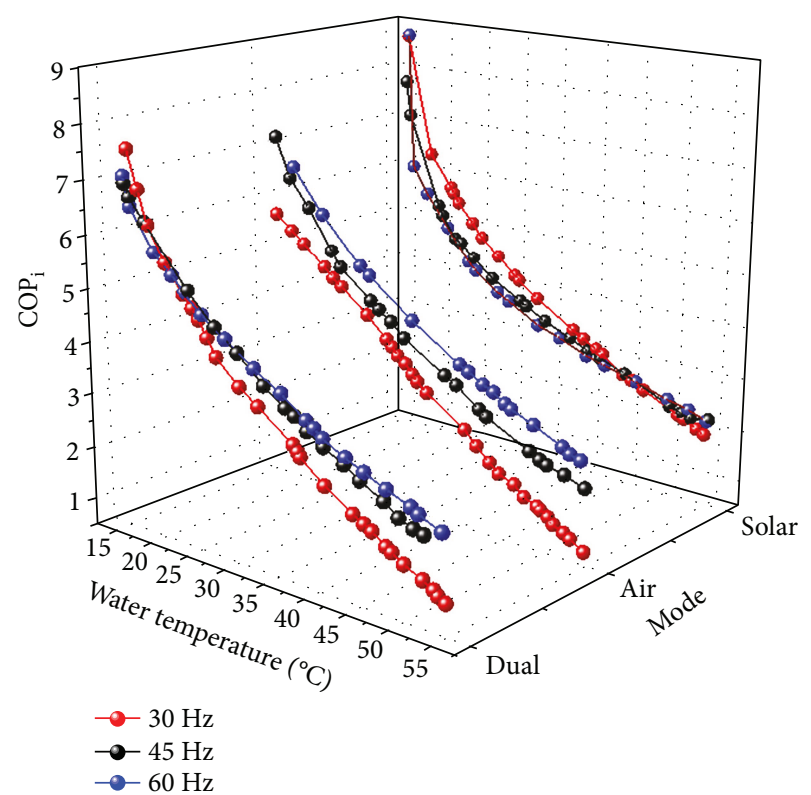

Figure 15: Effect of the compressor frequency on $\mathrm{COP}_{\mathrm{i}}$.

compressor frequency is higher. Because when the compressor frequency is higher, $Q_{e}$ is higher, which will speed up the heating process. In air and dual modes, $\mathrm{COP}_{\mathrm{m}}$ is higher when the compressor frequency is higher. So it is better to set the compressor frequency at $60 \mathrm{~Hz}$ for a higher $\mathrm{COP}_{\mathrm{m}}$ and less heating time under above conditions. In solar mode, $\mathrm{COP}_{\mathrm{m}}$ is lower when the compressor frequency is higher, so it is preferable to set the compressor frequency at $30 \mathrm{~Hz}$ for a higher $\mathrm{COP}_{\mathrm{m}}$ at the cost of longer heating time.

4.4. Comparison of Three Modes. Several experiments were tested in order to provide an operating strategy about the

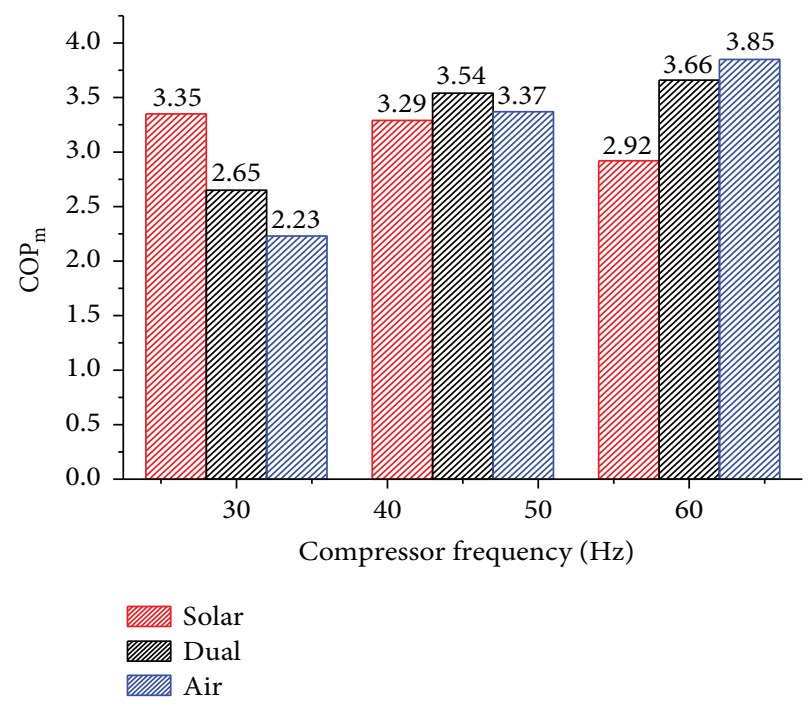

Figure 16: Effect of the compressor frequency on $\mathrm{COP}_{\mathrm{m}}$.

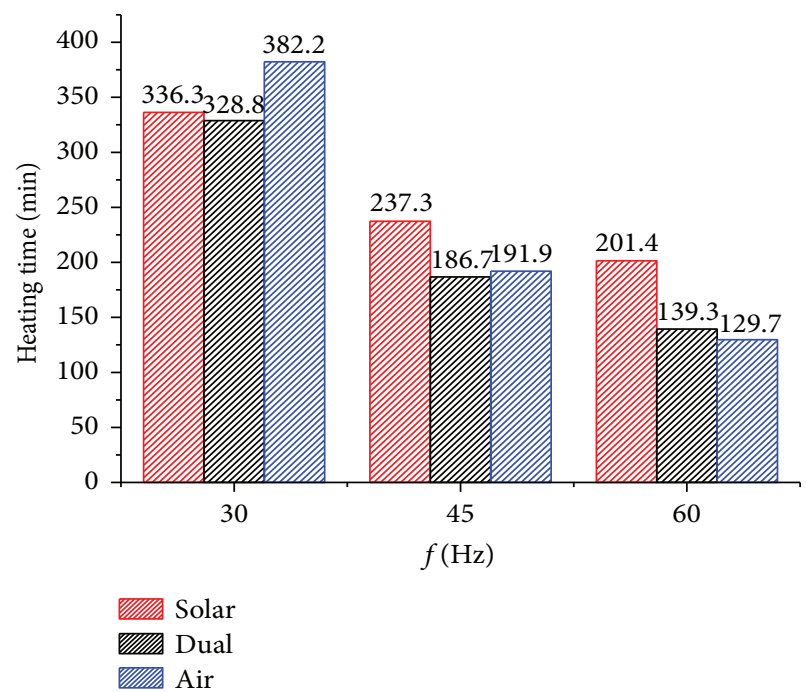

FIgURE 17: Effect of the compressor frequency on heating time.

operating mode and the compressor frequency under certain ambient conditions, results are shown in Table 5.

It is generally accepted that when the average COP is higher and heating time is less, the performance of heat pump water heater system is better. As shown in Table 5, under conditions that the solar irradiation is $900 \mathrm{~W} / \mathrm{m}^{2}$ and the ambient temperature is $20^{\circ} \mathrm{C}$ and $30^{\circ} \mathrm{C}$, in air and dual modes, it is better for this system to be operated at compressor frequency of $60 \mathrm{~Hz}$ for a relatively higher average COP and less heating time. And in solar mode, it is preferable to set the compressor frequency at $30 \mathrm{~Hz}$ for a higher average $\mathrm{COP}$ at the cost of longer heating time.

Under the conditions that the solar irradiation is $900 \mathrm{~W} /$ $\mathrm{m}^{2}$ and the ambient temperature is $30^{\circ} \mathrm{C}$, the system reaches the largest average COP of 4.15 in solar mode with the compressor frequency at $30 \mathrm{~Hz}$. While under above conditions, the system shows better performance in air mode with the 
TABle 5: Average COP and heating time under different ambient and operation conditions.

\begin{tabular}{|c|c|c|c|c|c|c|c|c|}
\hline \multicolumn{2}{|c|}{ Ambient conditions } & \multirow{2}{*}{ Compressor frequency } & \multicolumn{3}{|c|}{ Average COP } & \multicolumn{3}{|c|}{ Heating time (min) } \\
\hline Ambient temperature & Solar irradiation & & Air & Dual & Solar & Air & Dual & Solar \\
\hline \multirow{3}{*}{$20^{\circ} \mathrm{C}$} & \multirow{3}{*}{$900 \mathrm{~W} / \mathrm{m}^{2}$} & $30 \mathrm{~Hz}$ & 2.23 & 2.65 & 3.35 & 382.2 & 328.8 & 336.3 \\
\hline & & $45 \mathrm{~Hz}$ & 3.37 & 2.54 & 3.29 & 191.9 & 186.7 & 237.3 \\
\hline & & $60 \mathrm{~Hz}$ & 3.85 & 3.66 & 2.92 & 129.7 & 139.3 & 201.4 \\
\hline \multirow{3}{*}{$30^{\circ} \mathrm{C}$} & \multirow{3}{*}{$900 \mathrm{~W} / \mathrm{m}^{2}$} & $30 \mathrm{~Hz}$ & 3.40 & 3.48 & 4.15 & 260.0 & 262.2 & 276.3 \\
\hline & & $45 \mathrm{~Hz}$ & 4.12 & 3.96 & 3.88 & 147.9 & 167.2 & 200.9 \\
\hline & & $60 \mathrm{~Hz}$ & 4.07 & 3.97 & 3.61 & 122.8 & 128.6 & 161.7 \\
\hline
\end{tabular}

compressor frequency at $60 \mathrm{~Hz}$, because the heating time is much less and the average COP is only a little lower than 4.15.

As shown in Figure 15, when the ambient temperature, the solar irradiation, and the water temperature are different, the corresponding operating mode and the compressor frequency for a largest instantaneous COP are different. Thus, the operating mode and the compressor frequency should be chosen according to the ambient temperature, the solar irradiation, and the water temperature.

\section{Conclusion}

A novel DX-SAHPWH system was fabricated and tested experimentally in the enthalpy difference lab with a solar simulator. The effects of ambient temperature and solar irradiation on the performance of this system were analyzed. And the performance of the system in three operating modes with different compressor frequencies was compared by the paper.

(1) The ambient temperature, solar irradiation, and operating mode have almost no effect on the energy consumption of the compressor. When the ambient temperature and the solar irradiation are higher, $Q_{\mathrm{e}}$ and $\mathrm{COP}_{\mathrm{i}}$ are higher as well.

(2) With the rising of the water temperature, $W_{\text {sys }}$ increases while $Q_{e}$ and $\operatorname{COP}_{i}$ decrease. When the compressor frequency increases, $W_{\text {sys }}$ and $Q_{\mathrm{e}}$ both increase.

(3) It is therefore recommended to operate this system in air and solar modes with the compressor frequency at $60 \mathrm{~Hz}$ under an ambient temperature condition of $20^{\circ} \mathrm{C}$ to $30^{\circ} \mathrm{C}$ and an average solar irradiation of $900 \mathrm{~W} / \mathrm{m}^{2}$.

(4) In order to enhance the performance of this system, the operating mode and the compressor frequency should be chosen according to the water and ambient temperature, and solar irradiation.

\section{Nomenclature}

\section{Symbols}

W: $\quad$ Energy consumption, W
Q: $\quad$ Heat exchange rate, $\mathrm{W}$

$c: \quad$ Specific heat capacity, $\mathrm{J} /\left(\mathrm{kg}^{\circ} \mathrm{C}\right)$

m: $\quad$ Mass, $\mathrm{kg}$

T: $\quad$ Temperature, ${ }^{\circ} \mathrm{C}$

$t$ : Time, min

$\eta$ : $\quad$ Efficiency

$\mathrm{COP}_{\mathrm{i}}$ : Instantaneous coefficient of the performance

$\mathrm{COP}_{\mathrm{m}}$ : Average coefficient of the performance

$K$ : $\quad$ Convectional heat exchanging coefficient, $\mathrm{J} /\left(\mathrm{m}^{2}{ }^{\circ} \mathrm{C}\right)$

$\triangle T_{\mathrm{m}}: \quad$ Mean temperature difference, ${ }^{\circ} \mathrm{C}$

$\alpha$ : $\quad$ Absorptivity

$R: \quad$ Intensity of solar irradiation, $\mathrm{W} / \mathrm{m}^{2}$

$P$ : $\quad$ Pressure

$\gamma: \quad$ Compression index

$V_{\mathrm{d}}: \quad$ Displacement volume of compressor

$f: \quad$ Inverter frequency of compressor

$n$ : $\quad$ Rotating speed of compressor

$p$ : $\quad$ Motor magnetic series of compressor

$s: \quad$ Motor transfer ratio of compressor

$m_{\mathrm{r}}$ : Mass flow rate of refrigerant

$h_{\mathrm{r} \text { out }}$ : Refrigerant enthalpy leaving the evaporator-collector

$h_{\mathrm{r}, \mathrm{in}}$ : Refrigerant enthalpy entering the evaporator-collector

$v_{s}$ : Specific volume of refrigerant gas at compressor suction.

\section{Subscripts}

sys: $\quad$ System

com: Compressor

pump: Water pump

fan: Fan

ele: Electric controller

w: Water

e: Evaporator

$\mathrm{d}$ : Discharge end of compressor

s: $\quad$ Suction end of compressor

th: Theoretical

v: Volumetric

i: $\quad$ Indicated

m: Mechanical

mo: Motor

ini: Initial

fin: Final

1: $\quad$ Solar mode

2: $\quad$ Dual mode

3: $\quad$ Air mode. 


\section{Conflicts of Interest}

The authors declare that they have no conflicts of interest.

\section{Acknowledgments}

The work was supported by the National Science and Technology Support Program of China (no. 2015BAA02B03), Dong Guan Innovative Research Team Program (no. 2014607101008), and National Natural Science Foundation of China (no. 51378483).

\section{References}

[1] L. Yang, H. Yuan, J.-W. Peng, and C.-L. Zhang, "Performance modeling of air cycle heat pump water heater in cold climate," Renewable Energy, vol. 87, Part 3, pp. 1067-1075, 2016.

[2] S. Singh, M. Singh, and S. C. Kaushik, "A review on optimization techniques for sizing of solar-wind hybrid energy systems," International Journal of Green Energy, vol. 13, no. 15, pp. 1564-1578, 2016.

[3] Z. M. Amin and M. N. A. Hawlader, "Analysis of solar desalination system using heat pump," Renewable Energy, vol. 74, pp. 116-123, 2015.

[4] P. Sporn and E. R. Ambrose, "The heat pump and solar energy," in Proceeding of the world symposium on applied solar energy, 1955 November 1-5, 1955in Phoenix, Ariz.

[5] T. T. Chow, G. Pei, K. F. Fong, Z. Lin, A. L. S. Chan, and M. He, "Modeling and application of direct-expansion solar-assisted heat pump for water heating in subtropical Hong Kong," Applied Energy, vol. 87, no. 2, pp. 643-649, 2010.

[6] X. Q. Kong, D. Zhang, Y. Li, and Q. M. Yang, "Thermal performance analysis of a direct-expansion solar-assisted heat pump water heater," Energy, vol. 36, no. 12, pp. 6830-6838, 2011.

[7] M. Mohanraj, S. Jayaraj, and C. Muraleedharan, "Modeling of a direct expansion solar assisted heat pump using artificial neural networks," International Journal of Green Energy, vol. 5, no. 6, pp. 520-532, 2008.

[8] A. Moreno-Rodríguez, A. González-Gil, M. Izquierdo, and N. Garcia-Hernando, "Theoretical model and experimental validation of a direct-expansion solar assisted heat pump for domestic hot water applications," Energy, vol. 45, no. 1, pp. 704-715, 2012.

[9] W. Huang, J. Ji, N. Xu, and G. Li, "Frosting characteristics and heating performance of a direct-expansion solar-assisted heat pump for space heating under frosting conditions," Applied Energy, vol. 171, pp. 656-666, 2016.

[10] M. Mohanraj, S. Jayaraj, and C. Muraleedharan, "Exergy assessment of a direct expansion solar-assisted heat pump working with R22 and R407C/LPG mixture," International Journal of Green Energy, vol. 7, no. 1, pp. 65-83, 2010.

[11] X. Sun, J. Wu, Y. Dai, and R. Wang, "Experimental study on roll-bond collector/evaporator with optimized-channel used in direct expansion solar assisted heat pump water heating system," Applied Thermal Engineering, vol. 66, no. 1-2, pp. 571-579, 2014.

[12] L. Keliang, J. Jie, C. Tin-tai et al., "Performance study of a photovoltaic solar assisted heat pump with variable-frequency compressor - a case study in Tibet," Renewable Energy, vol. 34, no. 12, pp. 2680-2687, 2009.
[13] S. K. Chaturvedi, D. T. Chen, and A. Kheireddine, "Thermal performance of a variable capacity direct expansion solarassisted heat pump," Energy Conversion and Management, vol. 39, no. 3-4, pp. 181-191, 1998.

[14] L. Zhao, T. J. Zhang, Q. Zhang, and G. L. Ding, "Influence of two systematic parameters on the geothermal heat pump system operation," Renewable Energy, vol. 28, no. 1, pp. 35-43, 2003.

[15] B. J. Huang and J. P. Chyng, "Integral-type solar-assisted heat pump water heater," Renewable Energy, vol. 16, no. 1-4, pp. 731-734, 1999.

[16] X. Sun, Y. Dai, V. Novakovic, J. Wu, and R. Wang, "Performance comparison of direct expansion solar-assisted heat pump and conventional air source heat pump for domestic hot water," Energy Procedia, vol. 70, pp. 394-401, 2015.

[17] T. Changqing, S. Wenxing, and W. Sen, "Research on twostage compression variable frequency air source heat pump in cold regions," Acta Energiae Solaris Sinica, vol. 25, pp. 388-393, 2004.

[18] J. Ji, G. Pei, T.-t. Chow et al., "Performance of multi-functional domestic heat-pump system," Applied Energy, vol. 80, no. 3, pp. 307-326, 2005. 

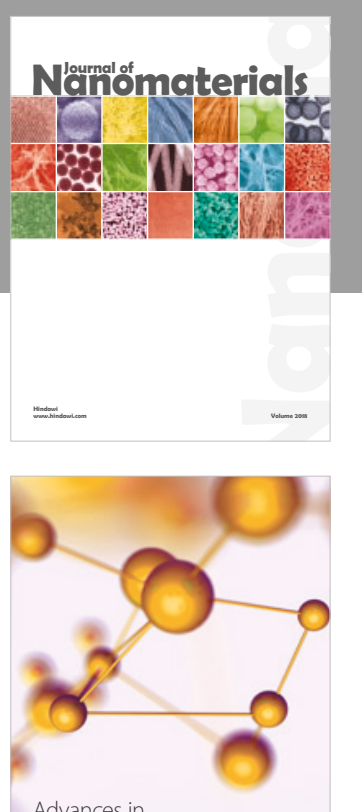

Physical Chemistry
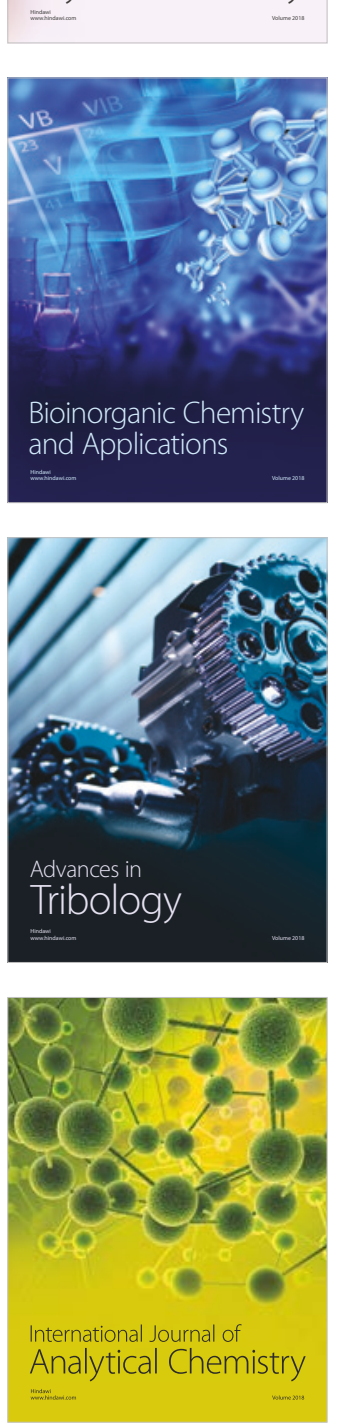

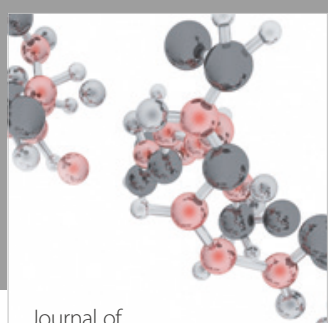

Analytical Methods

in Chemistry

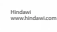

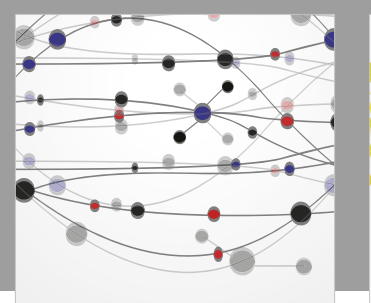

The Scientific World Journal

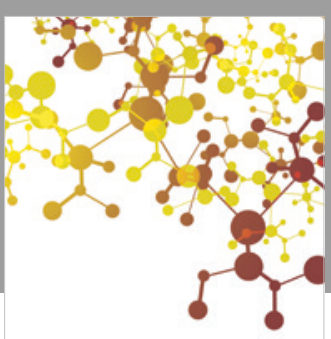

Journal of

Applied Chemistry
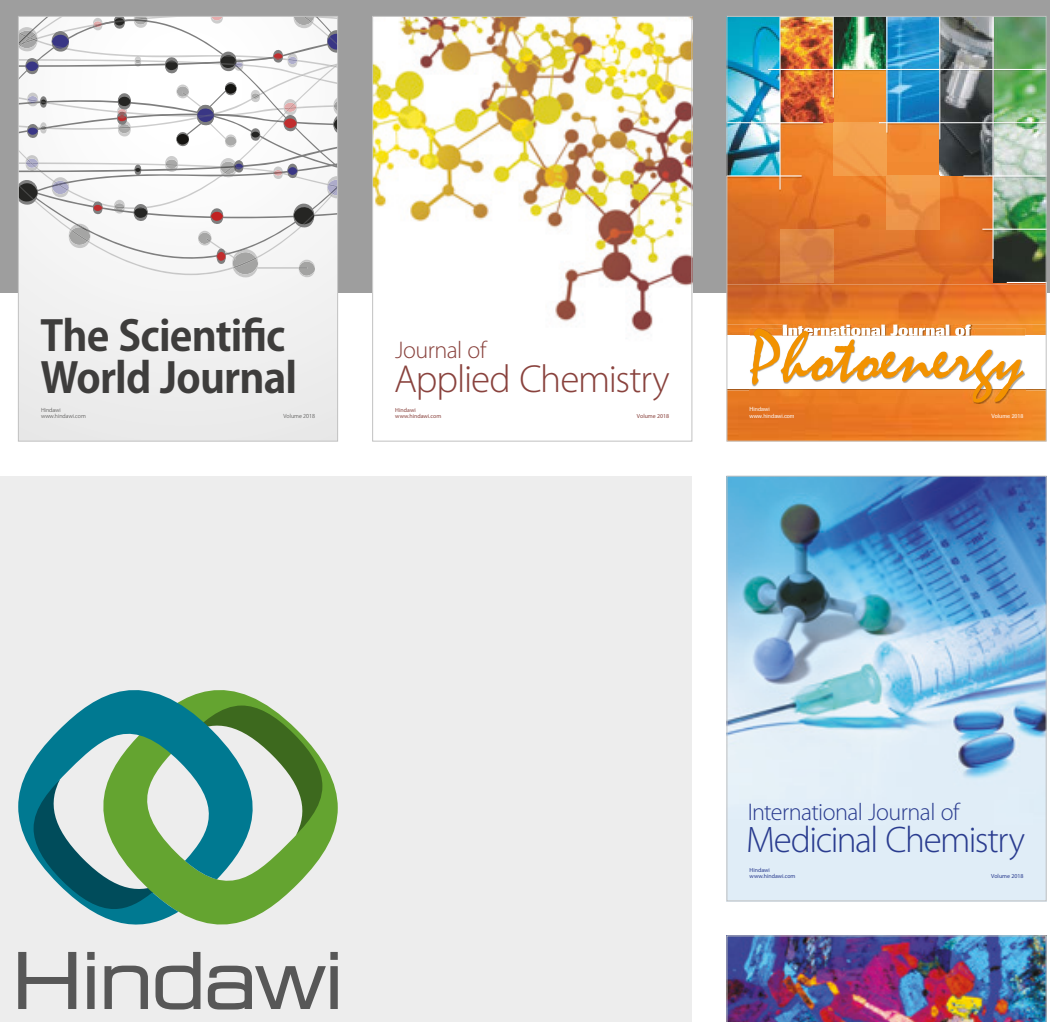

Submit your manuscripts at

www.hindawi.com
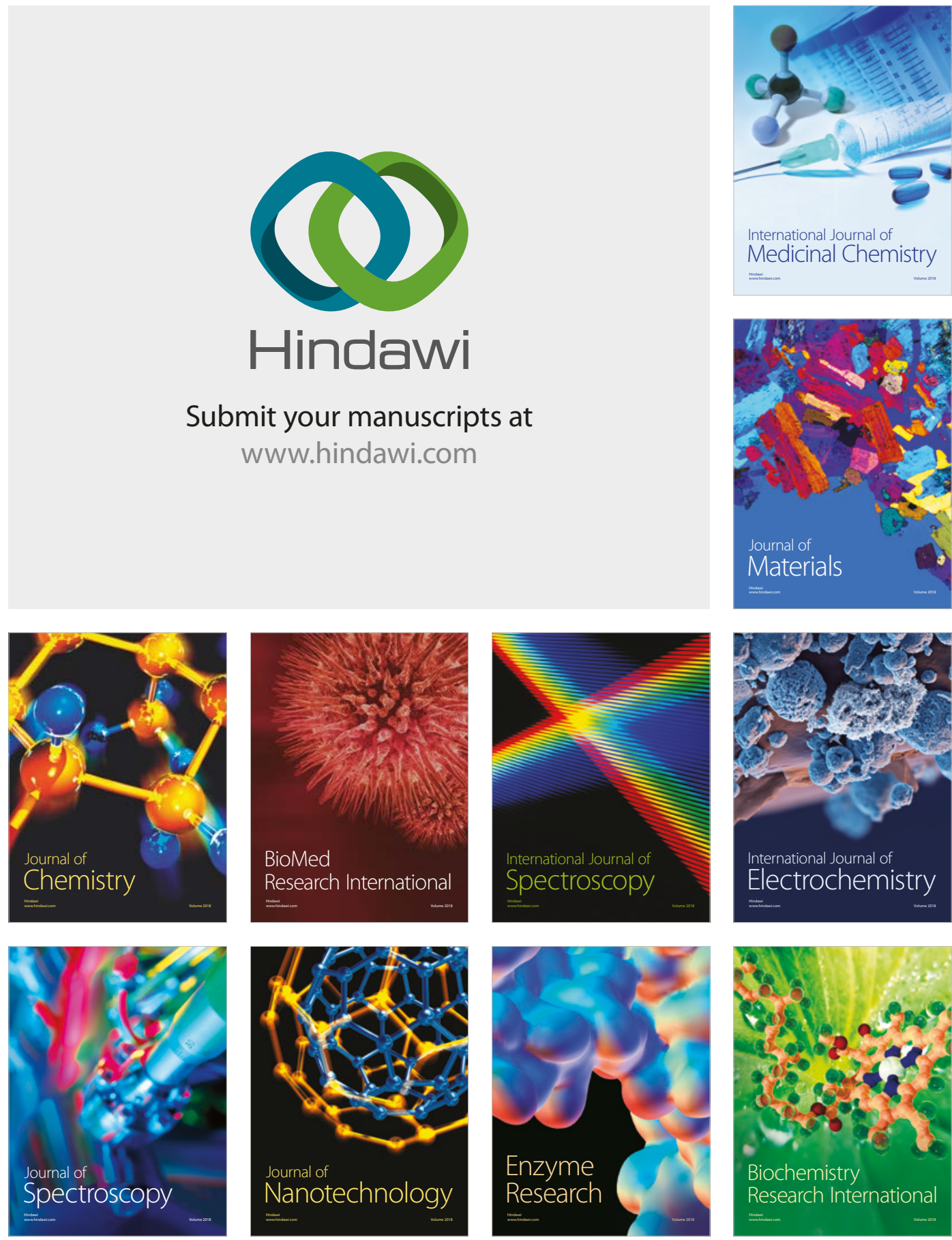
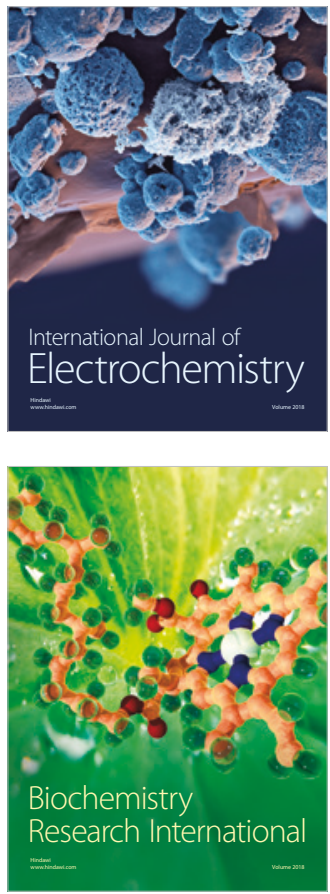